\title{
Composition of Ethanol-Insoluble Assimilatory Products of Oxidative Assimilation of Acetate by Euglena gracilis
}

\author{
BY G. MARZULLO AND W. F. DANFORTH \\ Department of Biology, Illinois Institute of Technology, Chicago 16, Illinois, U.S.A.
}

(Received 24 April 1963)

\section{SUMMARY}

After incubation for $6 \mathrm{hr}$. with uniformly labelled ${ }^{14} \mathrm{C}$-acetate, about $90 \%$ of the acetate carbon assimilated by non-photosynthetic Euglena gracilis var. bacillaris was in the form of cellular materials insoluble in $60 \%(v / v)$ ethanol in water. Within this fraction about $80 \%$ of the assimilated carbon was in the form of glucose units of the polysaccharide paramylon, about $9 \%$ was in a fraction containing proteins, nucleic acids and probably other materials, and about $2 \%$ was in lipid. The ratio of assimilated carbon to total carbon in the paramylon was 3 to 5 times that in the protein + nucleic acid or lipid fractions.

\section{INTRODUCTION}

Previous studies (Wilson \& Danforth, 1958; Danforth, 1961) showed that when a non-photosynthetic strain of Euglena gracilis var. bacillaris was incubated with acetate as a sole carbon and energy source, $42 \%$ of the acetate carbon was oxidized to $\mathrm{CO}_{2}$, while $58 \%$ was assimilated. Carbon: oxygen balance studies indicated that the assimilatory product(s) have the empirical composition of carbohydrate. When euglenas which have been permitted to utilize ${ }^{14} \mathrm{C}$-acetate are extracted with $60 \%(\mathrm{v} / \mathrm{v})$ ethanol in water, radioactive assimilatory products are found in both the ethanol-soluble and ethanol-insoluble fractions (Marzullo \& Danforth, 1964). The time course of labelling is quite different, however; the labelling of the soluble fraction increases rapidly at first, but soon steadies to a relatively constant value, while the rate of labelling of the insoluble is slow at first, increasing to a more rapid rate which is maintained while acetate assimilation continues. Kinetic analysis strongly suggests that some, but not all, of the soluble products serve as precursors for the insoluble material. The present work was directed toward identification of the ethanol-insoluble assimilation products.

\section{METHODS}

Organisms of a non-photosynthetic strain of Euglena gracilis var. bacillaris were grown, harvested, and washed by procedures described in preceding publications (Danforth \& Wilson, 1957, 1961). Incubation mixtures were prepared in Erlenmeyer flasks by suspending the washed euglenas in media composed of $0.035 \mathrm{M}$ sodium acetate uniformly labelled with ${ }^{14} \mathrm{C}$ and $0.002 \mathrm{M}$-sodium phosphate buffer (pH 7.0). The flasks were stoppered with cotton plugs and incubated at $25-27^{\circ}$ for $6 \mathrm{hr}$. The rate of oxygen consumption and the release of ${ }^{14} \mathrm{C}-\mathrm{CO}_{2}$ were measured 
in Warburg flasks containing the same mixtures and incubated at the same temperature, as described previously (Marzullo \& Danforth, 1964). A similar flask from which acetate was omitted was used to estimate the rate of endogenous respiration.

Figure 1 summarizes the following fractionation procedure. At the end of the incubation period, the euglenas were separated from the medium by centrifugation, washed three times with water, and resuspended in $60 \%(v / v)$ ethanol in water. This suspension was held at $65^{\circ}$ for $30 \mathrm{~min}$., then centrifuged. The pellet was washed twice by resuspension in $3 \mathrm{vol}$. of $60 \%(v / v)$ ethanol in water and recentrifugation. The supernatant fluid and washes were pooled and filtered by suction through a membrane filter; $0.5 \mathrm{ml}$. samples of this 'ethanol-soluble fraction' (ES) were dried on planchets and their radioactivity counted.

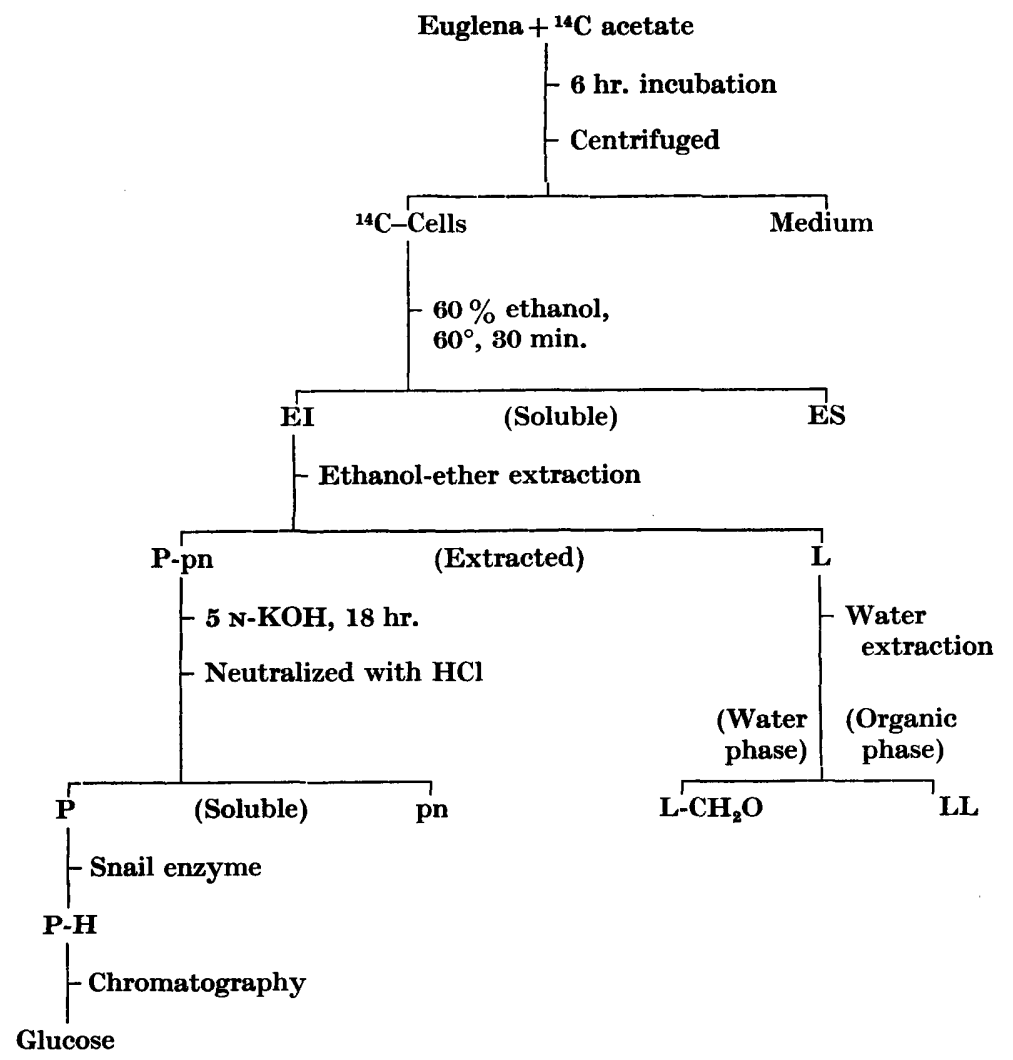

Fig. 1. Fractionation scheme for the separation of products of acetate assimilation.

The washed 'ethanol-insoluble fraction' (EI) was resuspended in $8 \mathrm{ml} .60 \%$ (v/v) ethanol in water, and samples counted for radioactivity. The remainder was dried to constant weight in a desiccator over $\mathrm{KOH}$.

The dried EI pellet was ground to a powder; $4 \mathrm{ml}$. of a mixture of $3 \mathrm{vol}$. ethanol + 1 vol. ether was added to the powder and the suspension was stirred for $30 \mathrm{~min}$. and centrifuged. The pellet was extracted three more times, and the ethanol+ ether extracts combined to form a 'lipid fraction' (L). This $L$ fraction, however, 
was found to contain carbohydrate, and was therefore re-extracted by shaking with 1.5 vol. water in a separatory funnel. The aqueous phase was re-extracted with $0.5 \mathrm{vol}$. fresh ether. The two organic fractions were combined (labelled ' $L L$ ') and the aqueous fraction labelled ' $\mathrm{L}-\mathrm{CH}_{2} \mathrm{O}$ '. Total carbohydrate and total radioactivity were determined on samples of both fractions, and the dry weight of the LL fraction determined.

The residue after ethanol + ether extraction (labelled ' $\mathbf{P}$-pn') was dried over $\mathbf{K O H}$ and weighed. Determinations of total carbohydrate, total nitrogen and radioactivity were made on samples of this fraction. Another sample of the P-pn fraction was placed in a $15 \mathrm{ml}$. conical centrifuge tube, and $2 \mathrm{ml} .5 \mathrm{~N}-\mathrm{KOH}$ added. The mixture was incubated at $55^{\circ}$ for $18 \mathrm{hr}$. A drop of $0.01 \%(\mathrm{w} / \mathrm{v})$ phenolphthalein indicator was added; the tube was placed in an ice bath and neutralized by dropwise addition of $\mathrm{N}-\mathrm{HCl}$ with careful stirring. More $\mathrm{HCl}$ was added to bring to pH 2.0 as tested with 'pHydrion' (Micro Essential Laboratory, Brooklyn 10, New York, U.S.A.) pH paper. Acidification of the clear KOH hydrolysate resulted in the formation of a flocculant gel-like precipitate. The precipitate was centrifuged down, washed six times with $0.01 \mathrm{~N}-\mathrm{HCl}$, and labelled ' $P$ ' (for paramylon). The washes were combined with the first supernatant fluid and labelled 'pn' (protein, nucleic acid). Determinations of total carbohydrate and reducing sugar were performed on the $\mathbf{P}$ fraction, and total carbohydrate, total nitrogen, and radioactivity were determined for the pn fraction.

A sample of the $P$ fraction was incubated at $37^{\circ}$ for $18 \mathrm{hr}$ in 0.05 M-sodium acetate buffer with an enzyme preparation extracted from snail intestines, known to contain $\beta$-glucosidase activity (L. Lerner \& A. H. Roush, personal communication). At the end of this time, the gel-like precipitate had dissolved. The enzymic digest was labelled ' $\mathrm{P}-\mathrm{H}$ ' (paramylon hydrolysate), and total carbohydrate and reducing sugar were determined on it.

The P-H fraction was then concentrated at room temperature under vacuum, and samples of the concentrate were chromatographed on Whatman no. 1 filter paper, with ethyl acetate + acetic acid + water $(9+2+2$, by vol. $)$ as a descending solvent. Authentic samples of glucose and ribose were used as markers. Reducing sugars were detected by spraying with a mixture of equal volumes of $0 \cdot 1 \mathrm{M}$-silver nitrate and $5 \mathrm{~N}$-ammonium hydroxide, and heated at $110^{\circ}$ for $10 \mathrm{~min}$.

Autoradiographs of chromatograms were made with Kodak Blue Brand X-ray film. Dises of Whatman no. 1 paper, which had been allowed to absorb amounts of P-H equivalent of $1,2,4,6$ and $10 \%$ of the amount chromatographed, were included in the autoradiographic procedure.

Total carbohydrate was determined by the anthrone method (Mokrasch, 1954; Trevelyan \& Harrison, 1952), reducing sugar by Nelson's (1944) method, and total nitrogen by Kjeldahl digestion followed by nesslerization (Johnson, 1941) with commercially prepared Nessler's reagent (Paragon C. and C. Co., Inc., New York 58, New York, U.S.A.).

Total carbon contents of the various fractions were estimated from dry weights on the assumption that carbon accounts for $40 \%$ of the weight of carbohydrate (polyglucose), $77 \%$ of the weight of lipid (stearo-oleopalmatin) and $50 \%$ of the weight of a mixture of protein $(55 \% \mathrm{C})$ and nucleic acid $(36 \% \mathrm{C})$. 


\section{RESULTS}

\section{Results of individual fractionation steps}

Table 1 summarizes the results of the extraction procedure for lipids. It may be seen that the original ethanol + ether extract $(L)$ contained a considerable amount of carbohydrate. Re-extraction of the ethanol + ether fraction with water removed this carbohydrate $\left(\mathrm{L}-\mathrm{CH}_{2} \mathrm{O}\right)$. Since carbohydrate accounted for most of the weight of the $\mathrm{L}-\mathrm{CH}_{2} \mathrm{O}$ extract, this material was combined with the paramylon fraction (P), while the purified ethanol + ether fraction (LL) served as the basis for determination of the ${ }^{14} \mathrm{C}$ assimilated as lipid.

Table 1. Characteristics of the lipid fraction at various stages of purification

\begin{tabular}{|c|c|c|c|c|}
\hline & \multicolumn{3}{|c|}{ Fraction } & \multirow{2}{*}{$\begin{array}{c}\% \\
\text { recovery }\end{array}$} \\
\hline & $\mathbf{L}$ & $\mathrm{L}-\mathrm{CH}_{2} \mathrm{O}$ & $\mathbf{L L}$ & \\
\hline Weight (mg.) & $16 \cdot 0$ & $(4 \cdot 0)$ & $12 \cdot 0$ & - \\
\hline Total counts/min. & 20,400 & 14,200 & 6,050 & 99 \\
\hline Carbohydrate (mg., as glucose) & $\mathbf{3} \cdot \mathbf{3 2}$ & $\mathbf{3} \cdot \mathbf{3 4}$ & Nil & 101 \\
\hline
\end{tabular}

$L=$ crude lipid fraction; $\mathbf{L}-\mathrm{CH}_{2} \mathrm{O}=$ water extract of $\mathrm{L} ; \mathrm{LL}=$ remainder after water extraction; the value in parentheses was estimated by difference.

Table 2. Distribution of dry weight and carbohydrate during subfractionation of the paramylon + protein + nucleic acid fraction

\begin{tabular}{|c|c|c|c|}
\hline & & ractio & \\
\hline & P-pn & $\mathbf{P}$ & pn \\
\hline Weight (mg.) & $113 \cdot 4$ & $73 \cdot 4$ & $(40 \cdot 0)$ \\
\hline Carbohydrate (mg. as glucose) & $76 \cdot 0$ & $75 \cdot 0$ & 0.71 \\
\hline
\end{tabular}

$\mathbf{P}$-pn $=$ paramylon + protein + nucleic acid fraction; $\mathbf{P}=$ paramylon fraction $;$ pn $=$ protein + nucleic acid fraction; value in parentheses estimated by difference.

Table 3. Distribution of carbohydrate and nitrogen during subfractionation of the paramylon + protein + nucleic acid fraction

\begin{tabular}{|c|c|c|c|}
\hline & \multicolumn{3}{|c|}{ Fraction } \\
\hline & P-pn & $\mathbf{P}$ & pn \\
\hline Carbohydrate (mg. as glucose) & $48 \cdot 6$ & 47 & $0 \cdot 85$ \\
\hline Nitrogen (mg.) & $\mathbf{1 . 9 7}$ & Nil & $\mathbf{1 . 9 3}$ \\
\hline
\end{tabular}

$\mathbf{P}$-pn $=$ paramylon + protein + nucleic acid fraction; $\mathbf{P}=$ paramylon fraction $;$ pn $=$ protein + nucleic acid fraction.

The rather unorthodox procedure used for separating paramylon $(P)$ from proteins and nucleic acids (pn) was developed empirically, based on characteristics of paramylon described by Clarke \& Stone (1960). The residue (P-pn) after ethanol + ether extraction was digested with strong base to hydrolyse proteins and nucleic acids. The paramylon dissolved during this step, but was precipitated by acidifying to $\mathrm{pH} 2 \cdot 0$. Tables 2 and 3 show analyses of the precipitates $(\mathrm{P})$ and supernates $(\mathrm{pn})$ after this step. All the nitrogen of the original material was found in the pn fraction. 
Most of the carbohydrate was found in the $\mathbf{P}$ fraction; the small amount of carbohydrate in the pn fraction can easily be accounted for by the pentose portions of the nucleic acids. The carbohydrate content accounted for the total weight of the $\mathbf{P}$ fraction, indicating that this material was essentially pure carbohydrate. The nitrogen content of pn was somewhat low for protein or nucleic acid, indicating that other materials may also have been present in this fraction.

Table 4 shows the results of digestion of the $\mathbf{P}$ fraction with snail enzyme. The total carbohydrate content of the fraction was unchanged during digestion, while reducing sugar, as glucose, increased from a negligible value to equal the total carbohydrate, indicating complete digestion of the polysaccharide to monosaccharides. Paper chromatograms of the digest showed a single reducing spot which corresponded to that for an authentic glucose sample.

Table 4. Results of hydrolysis of the paramylon fraction by snail enzyme

\begin{tabular}{|c|c|c|c|}
\hline & $\begin{array}{l}\text { Carbohydrate } \\
\text { (mg. as glucose) }\end{array}$ & $\begin{array}{l}\text { Reducing sugar } \\
\text { (mg. as glucose) }\end{array}$ & $\frac{\text { Reducing sugar }}{\text { Carbohydrate }}$ \\
\hline $\begin{array}{l}\text { Paramylon (P) } \\
\text { Hydrolysed paramylon }(\mathrm{P}-\mathrm{H})\end{array}$ & $\begin{array}{l}8 \cdot 00 \\
7 \cdot 80 \\
8 \cdot 20\end{array}$ & $\begin{array}{l}0 \cdot 004 \\
7 \cdot 90 \\
8 \cdot 20\end{array}$ & $\begin{array}{l}0 \cdot 0005 \\
1 \cdot 01 \\
1 \cdot 00\end{array}$ \\
\hline
\end{tabular}

Table 5. Gross ${ }^{14} \mathrm{C}$ balance after $6 \mathrm{hr}$. incubation of Euglena roith ${ }^{14} \mathrm{C}$-acetate

\begin{tabular}{|c|c|c|}
\hline & Counts/min. & $\mu$ g-atoms ${ }^{14} \mathrm{C}$ \\
\hline Total suspension & $1,250,000$ & 9,800 \\
\hline Medium & 800,000 & $\mathbf{6 , 2 0 0}$ \\
\hline \multicolumn{3}{|l|}{ Acetate- $\mathrm{C}$ utilized } \\
\hline Suspension minus medium & 450,000 & 3,540 \\
\hline Calculated from respiration & - & $\mathbf{3 , 8 2 0}$ \\
\hline \multicolumn{3}{|l|}{$\mathrm{CO}_{2}$} \\
\hline Measured & 198,000 & 1,550 \\
\hline${ }^{14} \mathrm{C}$ utilized minus ${ }^{14} \mathrm{C}$ assimilated* & 189,000 & $\mathbf{1 , 4 8 0}$ \\
\hline
\end{tabular}

* The amount of ${ }^{14} \mathrm{C}$ assimilated is the sum of ES and EI (Table 6).

\section{Gross carbon balance}

Table 5 shows the over-all carbon balance for one experiment in which euglenas were incubated with uniformly labelled ${ }^{14} \mathrm{C}$-acetate. It can be seen that the total acetate utilization determined by loss of radioactivity from the medium agrees well with that estimated from the oxygen consumption, and that two methods of estimating $\mathrm{CO}_{2}$ production from acetate are also in good agreement. The \% acetatecarbon converted to $\mathrm{CO}_{2}$ is very similar to that found in other studies (Wilson \& Danforth, 1958; Danforth, 1961).

Table 6 shows the distribution of ${ }^{14} \mathrm{C}$ among the various fractions in the same experiment. When expressed as \% total carbon assimilated, the results of a second experiment were very similar. About $8 \%$ of the carbon was found in the ethanolsoluble material, and the remaining $92 \%$ in the ethanol-insoluble material. Most of the insoluble radioactivity (75-80\% of all the carbon assimilated) was in the paramylon fraction, and much smaller amounts in the protein + nucleic acid and 
lipid fractions (about $10 \%$ and $2 \%$, respectively). In the last column in Table 6 , and also in Fig. 2, the ${ }^{14} \mathrm{C}$ content of each fraction is expressed as $\%$ of total carbon in that fraction.

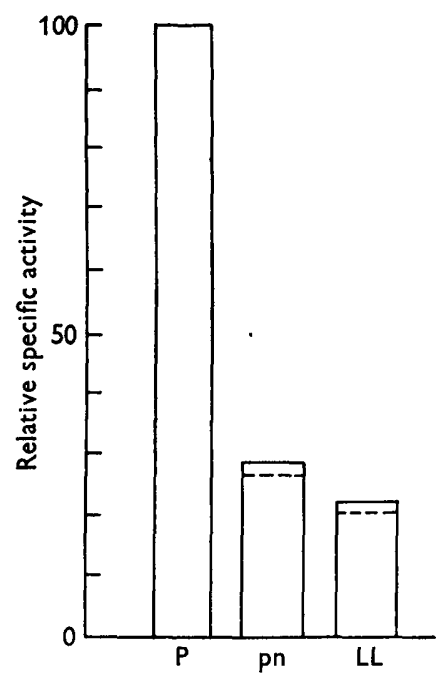

Fig. 2. Relative rates of carbon 'turnover' during the assimilation of acetate carbon by Euglena. 'Relative specific activity' of each fraction is the specific activity $\left({ }^{14} \mathrm{C} /\right.$ total $\mathrm{C}$ ) of the fraction expressed as \% specific activity of the paramylon fraction in the same experiment. P, Paramylon fraction; pn, protein-nucleic acid fraction; LL, lipid fraction. Bars represent the results of one experiment, and dotted lines the results of a second.

Table 6. Distribution of ${ }^{14} \mathrm{C}$ among various Euglena fractions after incubation for $6 \mathrm{hr}$. with ${ }^{14} \mathrm{C}$-acetate

\begin{tabular}{|c|c|c|c|c|}
\hline Fraction & Counts/min. & $\mu$ g.-atoms ${ }^{14} \mathrm{C}$ & $\begin{array}{c}\% \text { of } \\
\text { assimilated } \\
{ }^{14} \mathrm{C}^{*}\end{array}$ & $\frac{{ }^{14} \mathrm{C}}{(\%)}$ \\
\hline Ethanol-soluble (ES) & 20,900 & 164 & $8 \cdot 0$ & - \\
\hline Ethanol-insoluble (EI) & $\mathbf{2 4 0 , 0 0 0}$ & 1,880 & 92 & - \\
\hline Lipid (LL) & 6,050 & 47 & $2 \cdot 3$ & $6 \cdot 1$ \\
\hline $\begin{array}{l}\text { Paramylon + protein + nucleic } \\
\text { acid (P-pn) }\end{array}$ & 234,000 & 1,830 & 90 & - \\
\hline Protein + nucleic acid (pn) & 23,000 & 180 & $8 \cdot 8$ & $5 \cdot 0$ \\
\hline Paramylon (P) & 210,000 & 1,650 & 81 & $23 \cdot 2$ \\
\hline
\end{tabular}

Nature of the labelled material in the paramylon fraction

After enzymic digestion, the labelled P-H fraction was chromatographed, and the glucose spot, detected by silver nitrate spray, cut out. An amount of labelled P-H fraction identical with that chromatographed was absorbed on a bit of filter paper the same size and shape as the glucose spot. This 'dummy spot' was used to estimate the total radioactivity added to the chromatogram, corrected for selfabsorption of the filter paper. Table 7 shows the results of two experiments of this sort. It is apparent that essentially all (94-111\%) of the radioactivity originally applied to the chromatogram is found in the glucose spot. The degree of error in 
the counting method, however, is too great to preclude the possibility that some other labelled compound might be present in significant amounts. Therefore, autoradiographs of similar chromatograms were prepared. A 'dummy spot', containing ${ }^{14} \mathrm{C}$-labelled $\mathbf{P}-\mathrm{H}$ in an amount equivalent to $2 \%$ of that applied to the chromatogram, was included in the autoradiographic procedure. The resulting radiogram showed a spot corresponding to glucose, and a much weaker spot corresponding to the 'dummy', but no other spots. Therefore, it may be concluded that no component other than glucose accounted for as much as $2 \%$ of the radiocarbon in the paramylon fraction.

\section{Table 7. Radioactivity of the glucose spot in chromatograms of the hydrolysed paramylon $(\boldsymbol{P}-\mathrm{H})$ fraction}

The glucose spot was cut from the chromatogram; both sides of the spot were counted. $A$ 'dummy spot' contained an amount of P-H equal to the amount chromatographed, absorbed in a piece of filter paper the same size and shape as the glucose spot. Two 'dummy spots' were used in Expt. $I$.

\begin{tabular}{|c|c|c|c|c|c|c|c|}
\hline & \multicolumn{3}{|c|}{ Glucose spot } & \multicolumn{3}{|c|}{ 'Dummy spot' } & \multirow[b]{3}{*}{$\begin{array}{c}\text { Recovery } \\
(\%)\end{array}$} \\
\hline & Side 1 & Side 2 & Mean & Side 1 & Side 2 & Mean & \\
\hline & \multicolumn{6}{|c|}{ Counts/min. } & \\
\hline Expt. I & $70 \cdot 2$ & $\mathbf{5 8} \cdot \mathbf{0}$ & $64 \cdot 1$ & $\begin{array}{l}69 \cdot 0 \\
68 \cdot 0\end{array}$ & $\begin{array}{l}69 \cdot 0 \\
66 \cdot 0\end{array}$ & $68 \cdot 0$ & 94 \\
\hline Expt. II & $97 \cdot 3$ & $88 \cdot 0$ & $92 \cdot 7$ & $82 \cdot 5$ & $84 \cdot 2$ & $83 \cdot 4$ & 111 \\
\hline
\end{tabular}

\section{DISCUSSION}

Wilson \& Danforth (1958) concluded, on the basis of carbon balance studies, that nearly all the acetate-carbon assimilated by the euglenas used, under conditions similar to those of the present experiments, was converted to carbohydrate. The present results provide more direct support for this conclusion. About 75-80\% of the acetate-carbon assimilated was found in the form of glucose units of the reserve polysaccharide paramylon. Since some of the $8 \%$ of the ${ }^{14} \mathrm{C}$ found in the ethanolsoluble fraction is probably in the form of phosphorylated sugars, it seems likely that $80-90 \%$ of the acetate-carbon assimilated is converted to carbohydrate.

Under conditions of uniform growth, with acetate as sole carbon source, one would expect all cellular constituents to be synthesized at rates proportional to their abundance in the organisms. The results shown in Table 6 and Fig. 2 show that this is not the case in the present experiments. This almost certainly indicates that preferential net synthesis of carbohydrate is occurring, rather than synthesis of entire new euglenas. The alternative hypothesis, that the high rate of carbohydrate formation is compensated by a correspondingly high rate of carbohydrate degradation, can be ruled out; the required rate of degradation of intracellular carbohydrate would produce $\mathrm{CO}_{2}$ at a rate practically equal to the total rate of $\mathrm{CO}_{2}$ production in the presence of acetate. Experimentally, no more than one-third of the $\mathrm{CO}_{2}$ formed under these conditions is derived from intracellular material (Danforth, 1961; Danforth \& Wilson, 1961). Since the experimental media were deficient in nitrogen and vitamins, and since other experimental conditions (shaking, crowding, absorption of $\mathrm{CO}_{2}$ ) were probably unfavourable for growth, the preferential synthesis 
of carbohydrate may have been simply characteristic of non-growing organisms. Nitrogen deficiency (Witsch, 1948; Myers \& Cramer, 1948) or previous starvation (Cramer \& Myers, 1949) of Chlorella results in diversion of substrate assimilation toward carbohydrate synthesis; similar phenomena are known in a variety of other organisms.

On the other hand, respirometric studies (Wilson, 1963) on the closely related flagellate Astasia indicate that the \% of acetate-carbon assimilated $(42 \%)$ under growth conditions is identical with that found in Euglena (Wilson \& Danforth, 1958) under conditions resembling those of the present experiments. While the data under growth conditions do not permit construction of a complete carbon balance, it seems unlikely that the \% assimilation should remain unchanged if the assimilation products differed greatly under the two sets of conditions. A possible alternative explanation for the preferential synthesis of carbohydrate was suggested by Danforth \& Wilson (1961). On the basis of quite different considerations, they suggested that assimilation of rapidly utilized substrates such as acetate might at all times be directed primarily toward paramylon synthesis, and that energy and carbon for growth are derived secondarily, from breakdown of paramylon. At present, however, there is no direct evidence bearing on this question. Although assimilation of acetate-carbon appears to be channelled almost exclusively into carbohydrate synthesis, it cannot be assumed that this is true for all substrates, since the carbon balance for ethanol metabolism is not consistent with synthesis of carbohydrate as the sole assimilation product (Wilson \& Danforth, 1958).

This investigation was supported in part by a PHS Research Grant RG-7918 from the Division of General Medical Sciences, U.S. Public Health Service, and includes portions of a thesis presented by G. Marzullo in partial fulfilment of the requirements for the degree of Master of Science at Illinois Institute of Technology.

We are indebted to Mr L. Lerner (Department of Biochemistry, University of Illinois College of Medicine, Chicago 12, Illinois, U.S.A.) and Dr A. H. Roush (Department of Biology, Illinois Institute of Technology, Chicago 16, Illinois,U.S.A.) for a gift of snail enzyme.

\section{REFERENCES}

Clarke, A. E. \& Stone, B. A. (1960). Structure of the paramylon from Euglena gracilis. Biochim. biophys. Acta, 44, 161.

Cramer, M. \& Myers, J. (1949). Effects of starvation on the metabolism of Chlorella. Plant Physiol. 24, 255.

Danforth, W. F. (1961). Oxidative assimilation of acetate by Euglena. Carbon balance and effects of ethanol. J. Protozool. 8, 52.

Danforth, W. F. \& Wilson, B. W. (1957). Adaptive changes in the acetate metabolism of Euglena. J. Protozool. 4, 52.

Danforth, W. F. \& Wilson, B. W. (1961). The endogenous metabolism of Euglena gracilis. J. gen. Microbiol. 24, 95.

Johnson, M. J. (1941). Isolation and properties of a pure yeast polypeptidase. J. biol. Chem. 137, 575.

Marzullo, G. \& Danforth, W. F. (1964). Kinetic studies of the oxidative assimilaton of acetate by a non-photosynthetic strain of Euglena gracilis. J. gen. Microbiol. 34, 9.

Mokrasch, L. C. (1954). Analysis of the hexose phosphate and sugar mixture with the anthrone reagent. J. biol. Chem. 208, 55. 
Myers, J. \& Cramer, M. (1948). Metabolic conditions in Chlorella. J. gen. Physiol. 32, 103.

Nelson, N. (1944). A photometric adaptation of the Somogyi method for the determination of glucose. J. biol. Chem. 153, 375.

Trevelyan, W. E. \& Harrison, J. S. (1952). Fractionation and micro-determination of all carbohydrate. Biochem. J. 50, 298.

WILSON, B. W. (1963). Controlled growth and the regulation of the metabolism of the flagellates Astasia and Euglena. Thesis, University of California, Los Angeles.

Wilson, B. W. \& Danforth, W. F. (1958). The extent of acetate and ethanol oxidation by Euglena gracilis. J. gen. Microbiol. 18, 535.

Witsch, H. von (1948). Physiologischer Zustand und Wachstumsintensität bei Chlorella. Arch. Mikrobiol. 14, 128. 